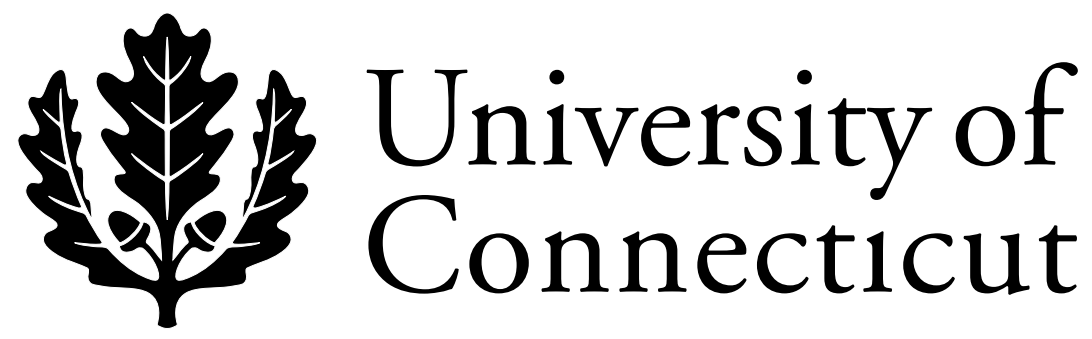

Department of Economics Working Paper Series

\title{
Rationality, Integrity, and Religious Behavior
}

Metin M. Cosgel

University of Connecticut

Lanse Minkler

University of Connecticut

Working Paper 2002-09R

May 2002

341 Mansfield Road, Unit 1063

Storrs, CT 06269-1063

Phone: (860) 486-3022

Fax: (860) 486-4463

http://www.econ.uconn.edu/

This working paper is indexed on RePEc, http://repec.org/ 


\begin{abstract}
Religions typically prescribe their followers to display distinct behavior in consumption, production, and exchange. Well-known are the examples of Catholics not eating meat on Fridays during Lent, Hindus being vegetarian and Muslims and Jews avoiding pork, Muslims praying five times a day, and Jews and Christians observing the Sabbath. As a common theme in these examples, individuals are asked to commit to a behavioral pattern by consistently choosing one course of action over its alternatives and not to deviate from the pattern even as circumstances (e.g., prices, cost, endowment) change. Although some followers of a religion may not be observing a prescribed behavior strictly and there may be some nonreligious individuals who might also be displaying the same pattern, that all followers typically observe the same pattern but with varying levels of compliance nevertheless suggests a source of behavioral commitment emanating from religious belief. Economists typically approach this type of behavior in one of two general ways. The first is to view religious behavior as being less rational or outright irrational and thus outside of the domain of economics. An alternative approach that has recently grown in popularity has been to provide economic explanations of the nature and consequences of religious behavior. These explanations typically apply economic concepts and models by viewing believers as rational consumers and religious organizations as clubs or firms that collectively constitute a religious market. Supply side factors like differences in opportunity sets, demand side factors like distinct preferences of believers, or social factors like peer-pressure have been variously proposed to explain distinct behavior. $1 \mathrm{We}$ advocate a third general approach in this paper by borrowing insights from other disciplines, particularly from philosophy. Identifying the weaknesses of previous economic explanations, we offer an alternative explanation that relies on philosophical discussions on the concept of integrity. We use the notion of integrity defined as identity-conferring commitments to develop an economic analysis of choice. Focusing on religious behavior, we use the analysis to show the way the influence of commitment on behavior differs from those of preferences and social pressure. We also discuss extensions of the argument to related issues such as the multiplicity of the dimensions of identity.
\end{abstract}




\section{Rationality, Integrity, and Religious Behavior}

Religions typically prescribe their followers to display distinct behavior in consumption, production, and exchange. Well-known are the examples of Catholics not eating meat on Fridays during Lent, Hindus being vegetarian and Muslims and Jews avoiding pork, Muslims praying five times a day, and Jews and Christians observing the Sabbath. As a common theme in these examples, individuals are asked to commit to a behavioral pattern by consistently choosing one course of action over its alternatives and not to deviate from the pattern even as circumstances (e.g., prices, cost, endowment) change. Although some followers of a religion may not be observing a prescribed behavior strictly and there may be some nonreligious individuals who might also be displaying the same pattern, that all followers typically observe the same pattern but with varying levels of compliance nevertheless suggests a source of behavioral commitment emanating from religious belief.

Economists typically approach this type of behavior in one of two general ways. The first is to view religious behavior as being less rational or outright irrational and thus outside of the domain of economics. An alternative approach that has recently grown in popularity has been to provide economic explanations of the nature and consequences of religious behavior. These explanations typically apply economic concepts and models by viewing believers as rational consumers and religious organizations as clubs or firms that collectively constitute a religious market. Supply side factors like differences in opportunity sets, demand side factors like distinct preferences of believers, or social factors like peer-pressure have been variously proposed to explain distinct behavior. ${ }^{1}$

\footnotetext{
${ }^{1}$ See Iannaccone (1998) for a review of this literature.
} 
We advocate a third general approach in this paper by borrowing insights from other disciplines, particularly from philosophy. Identifying the weaknesses of previous economic explanations, we offer an alternative explanation that relies on philosophical discussions on the concept of integrity. We use the notion of integrity defined as identity-conferring commitments to develop an economic analysis of choice. Focusing on religious behavior, we use the analysis to show the way the influence of commitment on behavior differs from those of preferences and social pressure. We also discuss extensions of the argument to related issues such as the multiplicity of the dimensions of identity.

\section{Why not Eat Pork? A Conversation of Economists on Religious Behavior}

Suppose you notice during a dinner reception at an academic conference of economists that two colleagues, whom you happen to know as being of the Jewish and Muslim faiths, choose fish over pork. Being a curious individual and a fan of roasted pork loin, you ask: "Why did you choose fish?" And both reply: "Because my religion prohibits me from eating pork."2 You are not satisfied with the answer because, although you know of the prohibitions against pork in these religions, you also vaguely remember other Jewish or Muslim colleagues who have had pork in similar receptions in the past. Other economists join the conversation and a heated debate starts. Realizing that the debate is about religion, some quickly leave the scene thinking that economists should shy away from such questions, while others rush in because they think economics provides powerful explanations of religious behavior. ${ }^{3}$

\footnotetext{
${ }^{2}$ For the historical roots of the prohibition of pork, see Lobban (1994).

${ }^{3}$ For a review of the relationship of religion to economics in intellectual history, see Welch and Mueller (2001). For examples and reviews of the recent literature on economics and religion, see Iannaccone (1998) and the contributions on the 1994 special issue (vol. 150, no. 4) of The Journal of Institutional and Theoretical Economics.
} 
One of them argues that the choice of fish follows directly from these colleagues' preferences, as shaped by their religious beliefs and patterns of socialization. She argues that preferences and choice behavior in general are shaped by the social, cultural, and religious environment. Given such preferences, her colleagues' choice of fish over pork is simply an instance of rational choice, based on the maximization of utility. To support these arguments, she mentions examples of work done on preferences and in the field of religious economics. ${ }^{4}$ Not everyone is convinced, however. Her Muslim colleague states: "I've never had pork in my life; how could I have formed preferences over it?" As the debate over the formation of preferences continues, some think that economists have little to say on preferences. Others seem afraid to discuss preferences in the first place.

Someone argues that tastes should be viewed as being stable over time and similar among people and that differences in behavior should be explained by differences in prices and incomes only (Gary Becker and George Stigler, 1977) He goes on to state: "Even in explaining religious behavior we would be better off focusing on differences in opportunity sets, rather than differences in preferences and beliefs." He gives examples of work done by Laurence Iannacconne and others that extended the Chicago school approach to the economics of religion. He quotes Iannacconne (1995: 77) as arguing: "the rational choice theorist is almost never content to explain [changes in religious behavior] with reference to changed tastes, norms, or beliefs." Confused, someone else asks: "What does that have to do with choosing fish over pork?" The reply comes that such dietary restrictions are simply examples of religious norms that constrain the behavior of members of religious groups in order to alleviate various externality problems (e.g., monitoring participation) that such groups are likely to face. These

\footnotetext{
${ }^{4}$ See, for example, Bowles (1998), Douglas and Isherwood (1979), George (2001), Granovetter (1985), Hausman and MacPherson (1994), Kuran (1994), McPherson (1983), and West and McKee (1983).
} 
norms affect behavior not by shaping the preferences but by restricting the opportunity set and making it costlier to choose the alternatives. The confusion appears to remain: "I'm still not clear. There would be no such cost to eating pork when one is alone, so what if someone still does not eat it?"

Someone watching all this quietly thus far joins the conversation at this point, stating: "This all boils down to social influence on choice. The real issue is not whether the choice of fish over pork follows from the demand side (preferences) or the supply side (opportunity set) alone, but how our choices are made in social settings and influenced by the social environment. Going back to your question: these colleagues would not choose pork over fish because they would be afraid that if seen eating pork they would be ostracized from their religious group." He mentions Timur Kuran's (1990) work on preference falsification, which suggests that social pressures might cause an individual to choose differently in public than in private. ${ }^{5}$ The Jewish colleague vehemently objects: "I have never had pork in my life, not even when I was all by myself with no one around to see me." The Muslim colleague nods his head in agreement. The ensuing discussion provides more examples of the consistency of most religious behavior between private and public settings, indicating that social pressure alone cannot explain why religious people display distinct behavior in consumption, production, and exchange. A consensus seems to emerge that a satisfactory explanation of religious behavior should go beyond preferences, opportunity sets, and social pressure.

Similar conversations can be heard elsewhere in trying to understand other types of religious behavior. Consider the allocation of time to worship and prayer. Supposing leisure and worship as being the only activities available, we can easily construct parallel arguments to explain how people choose these activities. The explanation of religious behavior based on 
distinct preferences would suggest that, given their religious upbringing and associated forms of worship, individuals have been socialized into receiving utility from worship and prayer.

Muslims would thus rather pray five times a day than spend the same time for leisure as a matter of preference, and similarly Jews and Christians prefer going to Synagogue and Church over leisure. Parallel explanations would emerge from supply side arguments and those emphasizing social pressure. For example, whereas the supply side arguments might explain these behaviors by focusing on the restricted set of activities available to individuals on the Sabbath, arguments based on social pressure might emphasize the way individuals pray and worship to avoid social pressure and to meet the expectations of friends and family members.

\section{Integrity}

To contribute to the discussion and understanding of religious behavior, we rely on philosophical insights on integrity. At its coarsest level, a person of integrity can be thought of as one who is honest and of character. Philosophers probe deeper. For instance, the Oxford Companion to Philosophy puts it this way:

To have integrity is to have unconditional and steady commitment to moral values and obligations. For such a person, the fundamental question whether to conduct life on the plane of self-concern or of moral seriousness has been decisively resolved, though particular life situations will doubtless continue to put that commitment to strenuous test. This moral commitment becomes a crucial component in his or her sense of identity as a person: it confers a unity of character... (p.410)

\footnotetext{
${ }^{5}$ See also Coşgel (1994) for audience effects that influence behavior.
} 
The notion of integrity we adopt is based on a body of research that emphasizes the roles of commitment and identity for human behavior and interaction. ${ }^{6}$ There are two requirements necessary for an individual to have integrity. The first is that he or she must have commitments. Commitments are internal requirements or constraints imposed on one's own self. ${ }^{7}$ What sorts of things could someone be committed to? Williams (in Smart and Williams, 1973: 112) suggests, "One can be committed to such things as a person, a cause, an institution, a career, one's own genius, or the pursuit of danger." Others, like McFall (1987), focus on personal and moral principles.

The second requirement is that these commitments define a person's identity. Virtually all philosophers who write on the subject concur that the commitments required by integrity must also be inextricably linked to one's own identity. That means that if one violates a commitment, say to temptation, one loses a sense of self. Utterances like "I could never do that" or "I couldn't live with myself if I did that" reflect the view that a committed person could not do "that" and remain the person they wish to be (Korsgaard 1994). Such a loss would be fundamental; it cannot be formulated as simply a loss in utility.

Taken together, these requirements indicate a definition of integrity as identity-conferring commitments. ${ }^{8}$ Before we apply this definition in economic analysis and examine its implications for religious behavior, we present some further observations on the philosophical discussions of commitment and integrity that should further clarify these notions for economists.

\footnotetext{
${ }^{6}$ For an analysis of the way identity can affect economic outcomes, see Akerlof and Kranton (2000), who incorporate the sociology and sociology of identity into an economic model of behavior.

${ }^{7}$ See, for instance, Halfon (1989) and Harcourt (1998). Sen (1977) was one of the first to introduce economists to the notion and importance of commitment. Frank (1987) provides an account of how commitments might be used strategically. Burke and Reitzes (1991) apply the identity approach to commitment in social psychology. Coşgel (2001) quantitatively examines the determinants of religious commitment.

${ }^{8}$ McFall (1987).
} 
Commitments are different from preferences. Being committed might prevent one from choosing preferred actions. Whereas economists consider preferences as exogenously determined desires, commitments are the product of conscious reflection. ${ }^{9}$ The distinction is crucial because the aim of economic man is to expeditiously fulfill desires in order to achieve maximal happiness, while a committed individual need not have such a primary goal. ${ }^{10}$ Recent work in social psychology suggests that well-being includes more than just happiness; it also includes meaning (McGregor and Little, 1998). Whenever commitments and desire conflict, the person of integrity is obligated to choose in favor of the former. ${ }^{11}$

McFall (1987) distinguishes between personal and moral integrity. A person of personal integrity must uphold commitments against temptation for personal principles, so that there is coherence between actions and principles. Someone who puts art above all else may thus have personal integrity. Moral integrity requires personal integrity, but also that the commitments must involve moral principles (e.g., "don't lie"). However, which moral principles qualify is somewhat problematic. A person of moral integrity must adhere to moral commitments for what he or she considers to be the right reasons, even if those reasons are suspect. Because specifying the correct moral principles in advance for every conceivable context can be problematic (impossible), Halfon (1989) suggests in the spirit of Aristotelian virtue ethics that a person of integrity simply be committed to "do what's best."

If one promises to suffer a loss of the most fundamental kind, one's own identity, by breaking a commitment, why would someone ever do so? Stated differently, why wouldn't

\footnotetext{
9 For Kantians, the source of this conscious reflection is a free will.

${ }^{10} \mathrm{McFall}$ (1987: 8) frames it this way: "If one values not just honesty but honesty for honesty its own sake, then honesty motivated by self-interest is not enough for integrity."

${ }^{11}$ Minkler and Miceli (2001) take integrity to be exogenously but differentially endowed to show that when all agents promise to cooperate, some won't, but some will in contraposition to their material interests.
} 
everyone enjoy unlimited integrity? We can think of three reasons. ${ }^{12}$ First, some people may not see the importance of identity-conferring commitments. Both the popular culture and the economist's approach to human behavior have propagated the notion that well-being consists solely in fulfilling desires. Some preference-satisfiers may even feign adhering to commitments in order to gain whatever else they desire. Second, some may wish to adhere to their own commitments but cannot because of weakness of will. Such people might succumb to desire but sincerely wish they had the ability not to. And third, some may break their commitments by rationalizing their actions, or by mentally changing their commitments for reasons of expedience but not recognize it as such. These are cases of self-deception.

We make two final points on integrity. First, integrity has been famously used by Williams (in Smart and Williams, 1973) to add yet another nail into utilitarianism's coffin. As we have emphasized, integrity requires adherence to one's own commitments (or projects). But utilitarianism requires one to treat one's own projects as just one set among many, and therefore a utilitarian is often compelled to violate his or her own projects in order to fulfill those of someone else. Thus utilitarianism cannot coherently include integrity. ${ }^{13}$ Secondly, while it is possible for someone else to violate one's dignity, only the person's own self can violate his or her own integrity (Halfon 1989). Each of us, and each of us only, are responsible for our own integrity.

\section{Identity, Commitment, and Religious Behavior}

We now consider these ideas more formally. We begin with the simple case of a single identity for each individual, assumed to be exogenously determined. To focus on religious

\footnotetext{
${ }^{12}$ The second and third points come from McFall (1987).
} 
behavior, we only consider religious identities, such as Jewish, Muslim, Catholic, Hindu, Lutheran, and so on. Of course, one could also be an atheist, follow lesser-known religions, or even have distinct personal religious beliefs.

Let $\mathbf{a}$ denote an action vector taken by an individual and $\mathbf{A}$ be the set of all available actions. All individuals have well-behaved preferences that obey the usual assumptions so that each individual has a unique utility-maximizing choice, denoted by $\mathbf{a}^{*}$ (that is, $\mathbf{a}^{*}$ solves Max $\mathrm{U}$ (a) subject to $\mathbf{p} \cdot \mathbf{a} \leq \mathrm{I}$, where $\mathbf{p}$ denotes prices and I income). $\mathbf{a}^{*}$ thus represents the action vector chosen based solely on personal preferences and without any consideration of identity or commitment.

Religious considerations are formulated as follows. Each religion prescribes either unique actions, denoted by $\overline{\mathbf{a}}$, or no specific actions, in which case individuals are free to do as they please, which simply means to choose $\mathbf{a}^{*}$. The final choice, however, depends on religious commitment and integrity. Each individual has a level of commitment to his or her given religious identity (be it Jewish, Muslim, etc.), denoted by c. Recall that c is the product of conscious reflection. Assume for simplicity that $\mathrm{c} \in[0,1]$ and that a higher value of $\mathrm{c}$ means a higher level of commitment. Applying the notion of identity discussed above, we can thus view $\mathrm{c}$ as the level at which commitments confer identity. Thus high $\mathrm{c}$ is associated with high integrity.

Given an individual's religious identity and the corresponding $\overline{\mathbf{a}}$, the level of commitment c, and the utility maximizing choice $\mathbf{a}^{*}$, he or she would choose a final action, denoted by $\mathbf{a}$, such that

\footnotetext{
${ }^{13}$ Harcourt (1998) extends the argument by suggesting that commitments, the core of integrity, are fundamentally at odds with utilitarianism and its reliance on preferences.
} 
$\hat{\mathbf{a}}=\mathrm{c} \overline{\mathbf{a}}+(1-\mathrm{c}) \mathbf{a}^{*}$

It is easy to see the choices corresponding to the extreme cases of individuals with $c=0$ (no commitment) and $\mathrm{c}=1$ (total commitment). The first is the type of individual who has no commitment to his or her religious identity and thus places no weight on religious prescriptions in choosing an action. As a result, $\hat{\mathbf{a}}=\mathbf{a}^{*}$. Put differently, this is the type of individual considered typical in standard theory of rational choice in economics. The second is the case of an individual totally committed to a religious identity and chooses actions based solely on religious considerations, so $\hat{\mathbf{a}}=\overline{\mathbf{a}}$. Individuals with $0<\mathrm{c}<1$ would display behavior of varying degrees of integrity that shows a compromise between utility maximization and religious prescriptions.

To illustrate, let us apply this setup to examples discussed above. In the example of dietary choice, $\overline{\mathbf{a}}$ would be to eat fish for a Jew, a Muslim, and a Catholic on Fridays during lent. For those with no specific restrictions, $\overline{\mathbf{a}}=\mathbf{a}^{*}$. Suppose in the absence of religious considerations individuals have convex preferences between pork and fish, in which case a* would include positive amounts of both fish and pork. By contrast, the final choice in our analysis depends on c. For example, a totally committed Jew $(\mathrm{c}=1)$ would choose fish only $(\hat{\mathbf{a}}=$ $\overline{\mathbf{a}})$, while one in name only $(c=0)$ would choose $\mathbf{a}^{*}$. Commitment levels between 0 and 1 would mean a partial observance of the religious prescription by including some pork in the diet. Figure 1 shows these possibilities graphically.

Figure 2 similarly shows the example of the allocation of time between worship and leisure. Suppose a religion prescribes an allocation at $\overline{\mathbf{a}}$, which includes some leisure and a high 
level of worship activities like performing personal prayers and attending weekly services. Suppose also that the utility maximizing allocation for an individual is at $\mathbf{a}^{*}$, with more leisure and less worship than that at $\overline{\mathbf{a}}$. By choosing $\mathbf{a}$ as shown, this individual is displaying a level of commitment strictly between 0 and 1 . An example of this type of an individual would be someone who occasionally chooses to play golf over attending the weekly service.

\section{Previous Explanations and their Limitations}

We can now use the analysis to put previous arguments about religious behavior into a unified framework. Recall that preference based arguments would typically view individuals as being conditioned to choose prescribed actions strictly as a matter of preference, which with our notation means $\mathbf{a}^{*}=\overline{\mathbf{a}}$. Based on this assumption, these arguments suggest $\hat{\mathbf{a}}=\overline{\mathbf{a}}$ because utility maximization requires $\hat{\mathbf{a}}=\mathbf{a}^{*}$ always, by assumption. We get the same result, but for a different reason. In our analysis $\hat{\mathbf{a}}=\overline{\mathbf{a}}$ because (still assuming $\mathbf{a}^{*}=\overline{\mathbf{a}}$ ), $\hat{\mathbf{a}}=\mathrm{c} \overline{\mathbf{a}}+(1-\mathrm{c}) \mathbf{a}^{*}=\mathbf{a}^{*}$ for all c. In this case, the standard neoclassical result is nested in our analysis including commitment.

Supply side arguments would view individuals as choosing prescribed actions not as a matter of preference but because the alternatives are not available. With our notation this means to assume a restricted action set, $\mathrm{A}^{\mathrm{r}}$, such that $\mathbf{a}^{*} \notin \mathrm{A}^{\mathrm{r}}$ and that in extreme cases perhaps even $\hat{\mathbf{a}}=$

$\overline{\mathbf{a}}$. For example, the sale of pork may be prohibited in Islamic countries, so individuals would have no choice but not to eat it (and thus eat only fish in the above example). Our analysis also includes that possibility, but additionally one could choose not to eat pork because of religious 
commitment regardless if the supply constraint is binding. As long as $\overline{\mathbf{a}} \in \mathrm{A}^{\mathrm{r}}$, the alternative reason one might choose $\overline{\mathbf{a}}$ is because $\mathrm{c}=1$.

Finally, explanations that emphasize social pressure can be formulated in our analysis as implying the presence of some social cost to deviating from the prescribed action: a disutility, denoted by d, whenever $\mathbf{a} \neq \overline{\mathbf{a}}$. Regardless of $\mathrm{c}$, the individual may thus choose $\hat{\mathbf{a}}=\overline{\mathbf{a}}$ because $\mathrm{u}\left(\mathbf{a}^{*}\right)+\mathrm{d} \leq \mathrm{u}(\overline{\mathbf{a}})$

The final choice in these arguments is guided directly by the distinct preferences of religious people, constrained by the available opportunities, or dictated by social pressure. Although we do not deny that any one of these reasons could indeed be the reason in some contexts, we nevertheless argue that such explanations fail to explain observed behavior in all cases. Individuals often follow the religious prescription even when it demands preference falsification $\left(\hat{\mathbf{a}} \neq \mathbf{a}^{*}\right)$, alternatives are readily available $\left(\mathbf{a}^{*} \in \mathbf{A}\right)$, and social pressure is absent (d $=0$ ). For example, although the presence of distinct preferences might explain the case of a Catholic who goes to church every Sunday only because he or she truly enjoys the experience, it does not explain why the same person would observe the lent (thus avoid a preferred item). It similarly does not explain why Muslims fast from dusk until dawn during the month of Ramadan. The supply-side explanations similarly fail to explain why a Jew, who would rather (strictly as a matter of preference) go shopping on a Saturday, ends up going to the Synagogue even when the malls are open (thus no restriction on the opportunity).

Our emphasis on integrity also identifies a significant failure of the explanations of religious behavior based on social pressure. These explanations generally fail to explain why people display the same behavior when no one else is present to observe. There is, of course, an 
important social component to religious behavior, which we do not deny. It is indeed possible that someone might attend the weekly service to prevent his nosy neighbor from spreading rumors, or two Muslims might avoid pork and alcohol in a restaurant while eating together. These do not explain, however, why an individual would attend the service even when the neighbors are on vacation, or perhaps most fundamentally, why a Muslim would avoid pork and alcohol even when dining alone at home.

Rather than external pressure or restricted opportunities, we emphasize factors that are internal to an individual as influencing the choices of actions. Moreover, rather than confining internal influences to the realm of preferences, we emphasize integrity and commitment. Note, however, that emphasizing commitment is not the same as arguing that individuals always follow religious prescriptions. Between the extremes of an individual depicted by the standard choice theory $(\mathrm{c}=0)$ and a totally committed individual $(\mathrm{c}=1)$ is the (majority of ?) population who for one reason or another have chosen an intermediary level of commitment to their religious identities.

\section{Multidimensional Identity}

We now generalize the analysis by considering identity as a multidimensional concept. Each individual exists in the world not only as a religious believer but also possibly as a parent, worker, friend, spouse, activist, and so on, which jointly constitute his or her identity and sense of self. ${ }^{14}$ Specific dimensions of each person's identity would of course be determined by such things as biological characteristics and social environment. Someone could be a 30 year old Catholic male, single, and working as an engineer in a local factory, while someone else could be a 40 year old Southern Baptist, female, married with two children, and unemployed. Although 
an individual may be able to choose many of these dimensions, such as whether to be married and have children, we assume below that one's identity is exogenously determined. The choice of these dimensions is certainly an important subject, but outside the scope of this paper. We assume identity is given, in order to keep the analysis simple and focused on commitment.

Let $\mathbf{a}^{*}$ denote utility maximizing actions as before. Identity considerations are formulated as follows. Suppose there are n dimensions to one's identity. Corresponding to dimension $\mathrm{j}$ is a prescribed action set denoted by $\overline{\mathbf{a}}^{\mathbf{j}}$, which for simplicity we assume to be unique and public knowledge. For example, as workers we are expected to devote a certain amount of our time to work; as parents we are expected to spend a certain amount of time with our children, and as believers we are expected to allocate time for worship and prayer. Each of these dimensions clearly indicates a different prescribed allocation of our time between work, leisure and worship.

Given the dimensions of an individual's identity and the corresponding prescribed actions, he or she chooses a level of commitment, denoted by $\mathrm{c}^{\mathrm{j}}$, to each dimension $\mathrm{j} . \mathbf{c}=\left[\mathrm{c}^{1}, \mathrm{c}^{2}\right.$, $\left.\ldots c^{n}\right]$ thus has the important component of deciding how much of our resources and attention to devote to each dimension, based on our overall purpose in life and the kind of person we would like to be. The notion of integrity adopted here views $\left[c^{1}, c^{2}, \ldots c^{n}\right]$ as the set of commitments that confers one's identity and sense of self.

Because of scarce time and resources, we may not be able to fully commit to all dimensions of our identity. To formalize this constraint, we interpret $\mathrm{c}^{\mathrm{j}}$ as showing the relative weight attached to identity $\mathrm{j}$, higher values of $\mathrm{c}^{\mathrm{j}}$ indicating higher levels of commitment. Put differently,

\footnotetext{
${ }^{14}$ For similar multiplicities of identities in economic models, see Elster (1986) and Kuran (1990).
} 
$\sum_{\mathrm{j}} \mathrm{c}^{\mathrm{j}}+\mathrm{s}=1$,

where $s$ is the weight attached to the self that places no consideration on identity. Identity considerations affect the final choice of an action as follows. Given the prescribed actions for each identity $\overline{\mathbf{a}}^{\mathbf{j}}$, the commitment vector $\mathbf{c}$, and the utility maximizing choice $\mathbf{a}^{*}$, an individual chooses final actions, denoted by $\mathbf{a}$, such that

$$
\hat{\mathbf{a}}=\sum_{\mathrm{j}} \mathrm{c}^{\mathrm{j}} \overline{\mathbf{a}}^{\mathrm{j}}+\mathrm{s} \mathbf{a}^{*} .
$$

Extreme cases of individuals with $\mathrm{c}^{\mathrm{j}}=0$ (no commitment) and $\mathrm{c}^{\mathrm{j}}=1$ for some identity $\mathrm{j}$ (total commitment) are similar to those discussed earlier in the simpler analysis with a single (religious) identity. The first is an individual who places no weight on a certain dimension of his or her identity, which would be the case, for example, if a father imposes no internal requirement on himself to contribute to his children's upbringing and thus devotes no time or resources for that purpose (unless it happens to coincide with his preferences). By contrast, the second is the type of an individual exclusively committed to a certain identity, such as would be the case when someone commits his or her life to a religious cause (e.g., an imam, rabbi, or priest) and spends all of his or her time for this cause, so that $\hat{\mathbf{a}}=\overline{\mathbf{a}}^{\mathbf{j}}$. For any $\hat{\mathbf{a}} \# \overline{\mathbf{a}}^{\mathbf{j}}, \mathbf{c}$ is less than its required level. That could happen either because the individual does not feel entirely committed to the principle underlying the action, or even if he does he does not have time or resources because of competing identities and their obligations. Note also the case of $\sum_{\mathrm{j}} \mathrm{c}^{\mathrm{j}}=0($ or $\mathrm{s}=1)$, in which case an individual places no weight at all on identity considerations in choosing an action. As a result $\hat{\mathbf{a}}=\mathbf{a}^{*}$, displaying the type of behavior considered typical in standard theory of rational choice in economics. 


\section{Extensions and Related Issues}

Recognizing the multidimensionality of identity shows the limitations of considering integrity as a one-dimensional concept. Previous discussions of integrity consider it as being either present or absent in an individual. For instance, recent economic formulations of integrity consider it as a continuum, but still in one dimension (Minkler and Miceli, 2001). It is easy to see that these are special cases of the analyses developed above. The formulation of integrity as a single dimensional continuum is in some sense identical to the simple analysis presented earlier for the special case of a single (religious) identity for each individual. Integrity in that context was a matter of making commitments that confer identity, formalized by the level of c. Similarly, considering integrity in the more limited sense of being either present or absent would be the same as formulating $\mathbf{c}$ as a binary variable that allows only two choices to individuals: to commit or not to commit to identity. Although both of these formulations can certainly be useful, we have to recognize their limitations in making general observations. Unless we can somehow produce a metric that can measure $\left[c^{1}, c^{2}, \ldots c^{n}\right]$ as a single quantity, we have to be careful about making general statements about integrity in a broader sense. We can easily imagine someone who is a committed spouse but a lousy believer. Philosophers insist that integrity requires coherence: consistency among one's commitments and consistency among commitments and actions. But even if one holds consistent commitments, the resource constraint posed by competing identities might mean that an otherwise sincere and committed person cannot consistently fulfill some of his obligations. Absent criteria to prioritize and quantify the "values" of different dimensions of identity, we simply have no way of assigning a single level of integrity to these individuals. We may be left with Halfon's (1989) characterization of a person of integrity as simply being committed to "doing what's best." 
Considering identity as a multidimensional concept allows us to examine the relationship between the religious dimension of our identities and other dimensions. The alternatives to the religious dimension of our identities can be divided into two general categories. The first is the "utility maximizing" self, whose choice of $\mathbf{a}^{*}$ was formalized in the analysis as receiving the weight s. As discussed earlier, economic models typically consider this as the only relevant dimension of our selves, so $\mathrm{s}=1$ corresponds to the type of behavior considered typical in standard theory of choice. It is well known that economists typically consider the satisfaction of one's own preferences as the only motivation for choice. Even alternative motivations, such as one's concern for the well-being of others, are modeled as a matter of preference, as somehow being part of one's own utility function. Although we do recognize that preference satisfaction is a motivation for choice, we also include and emphasize commitment, thus permitting a fuller characterization. Thus, s represents the degree to which we yield to the part of our selves exclusively concerned about the maximization of utility, regardless of its contents. Put differently, $\mathrm{s}$ is the degree of self-interest.

The second category of alternatives to the religious dimension is the other dimensions of integrity in our identity. There are certain parallels between our analysis and the models of consumption choices that suggest a useful analogy to characterize the relationship between two dimensions of integrity. Just as two goods can be substitutes and complements, two dimensions of integrity can substitute or complement each other. For example, there are numerous elements of being a parent and a religious believer that make them complementary to each other. Being a committed believer and a committed parent often go together, such as for parents who view teaching religion to their children and taking them to religious activities as essential components of parenthood. By contrast, being a worker and a religious believer are often substitute 
dimensions of one's identity. A Muslim has to take time off from work to be able to attend the Friday prayer, and a workaholic Christian cannot work on Sunday without violating the rules for the Sabbath.

Distinguishing between substitutes and complements provides a way to examine how changes in other dimensions of our lives can affect our religious commitment and behavior. We can view this in two ways. The first is within a static, "partial equilibrium" framework, where a given change in the commitment level of another dimension can cause religious commitment to change. For example, the complementarities between parenthood and religiosity indicate that one might become more religious upon having a child. Similarly, one might be less religious after being promoted at work to a position that demands a higher level of commitment.

The other way to examine changes in commitment levels is in a "general equilibrium" framework that considers the overall interdependence between the levels of commitment in a dynamic setting. For example, the individual who becomes more religious after having a child may in turn decide to have even more children, as some religions prescribe. Similarly, he or she may become less committed to work or take a less demanding job. Individuals typically seek coherence in their identity, which requires a stable equilibrium in commitment levels. "Externalities" between different dimensions of one's identity mean that an increasing commitment to one dimension would lead to higher levels of commitment in complementary dimensions and lower levels in substitute dimensions, until a new coherent identity is achieved at a new stable equilibrium.

Explicit formulation of integrity, identity, and commitment in an economic model would allow economists to provide fresh perspectives to well-known problems and pursue new areas of research. For example, one of the well-known problems in welfare economics is the distinction 
between preferences and beliefs as the basis for public policy (Hausman and McPherson, 1994; Sagoff, 1986). Whereas economists typically view preferences as "hard data" and prescribe policy based on them, we view this approach as being too simplistic because individuals choose how much weight to assign to their preferences, and superimposing a $100 \%$ weight $(\mathrm{s}=1)$ to their preferences is unwarranted. Note also that an integrity-based approach provides a different perspective on the literature of metapreferences (Sen, 1977) by showing the way identity conferring commitments, rather than higher order preferences, determine our choices of preferences and actions.

Finally, the hardest task ahead is to find way to explicitly model the choice of commitments. The difficulty arises because commitments are the product of conscious reflection. While we treated commitments the same way an economist would treat preferences, namely as being exogenous, future efforts will need to open the black box. Whereas commitments, like preferences, may be significantly influenced by the interplay between genetics and social forces, they also involve free will and conscious reflection, which add a meta-physical dimension to the analysis. 


\section{Works Cited}

- Akerlof, George A. and Rachel E. Kranton. 2000. "Economics and Identity," Quarterly Journal of Economics 115(3): 715-53.

- $\quad$ Bowles, Samuel. 1998. "Endogenous Preferences: The Cultural Consequences of Markets and other Economic Institutions," Journal of Economic Literature 36: 75-111.

- $\quad$ Burke, Peter J. and Donald C. Reitzes. 1991. "An Identity Theory Approach to Commitment," Social Psychology Quarterly 54(3): 239-51.

- Coşgel, Metin M. 1994. "Audience Effects in Consumption," Economics and Philosophy 10: 19-30.

- $\quad$ Coşgel, Metin M. 2001. "The Commitment Process in a Religious Commune: The Shakers," Journal for the Scientific Study of Religion 40(1): 27-38.

- $\quad$ Douglas, Mary and Baron Isherwood. 1979. The World of Goods. New York: Basic Books.

- $\quad$ Elster, Jon. 1986. The Multiple Self. Cambridge: Cambridge University Press.

- $\quad$ Frank, Robert H. 1987. "If Homo Economicus Could Choose His Own Utility Function, Would He Want One with a Conscience?" The American Economic Review 77: 593-604.

- George, David. 2001. Preference Pollution: How Markets Create the Desires We Dislike. Ann Arbor: University of Michigan Press.

- $\quad$ Granovetter, Mark. 1985. "Economic Action and Social Structure: The Problem of Embeddedness," American Journal of Sociology 91(3): 481-510.

- Halfon, Mark. 1989. Integrity: A Philosophical Inquiry. Philadelphia: Temple University Press.

- Harcourt, Edward. 1998. "Integrity, Practical Deliberation and Utilitarianism," The Philosophical Quarterly 48(19): 187-98.

- $\quad$ Hausman, Daniel M. and Michael S. McPherson. 1994. "Preference, Belief, and Welfare," The American Economic Review 84(2): 396-400.

- $\quad$ Iannaccone, Laurence R. 1995. "Voodoo Economics? Reviewing the Rational Choice Approach to Religion," Journal for the Scientific Study of Religion 34: 76-88.

- Iannaccone, Laurence R. 1998. "Introduction to the Economics of Religion," Journal of Economic Literature 36: 1465-96.

- Korsgaard, Christine. 1994. "The Sources of Normativity," The Tanner Lectures on Human Values. vol. 15, Edited by Grethe Peterson, Salt Lake City: University of Utah Press.

- $\quad$ Kuran, Timur. 1990. "Private and Public Preferences," Economics and Philosophy 6: 126.

- Kuran, Timur. 1994. "Religious Economics and the Economics of Religion,” Journal of Institutional and Theoretical Economics 150: 769-75.

- $\quad$ Lobban, Richard A. Jr. 1994. "Pigs and their Prohibition," International Journal of Middle Eastern Studies 26: 57-75.

- McFall, Lynne. 1987. "Integrity," Ethics 98: 5-20.

- $\quad$ McGreggor, Ian, and Brian Little. 1998. "Personal Projects, Happiness and Meaning: On Doing Well and Being Yourself," Journal of Personality and Social Psychology 74(2): 494-512.

- $\quad$ McPherson, Michael S. 1983. "Want Formation, Morality, and Some 'Interpretive' Aspects of Economic Inquiry," In Social Science as Moral Inquiry, edited by Norma 
Haan, Robert N. Bellah, Paul Rabinow and William M. Sullivan, pp. 96-124. New York: Columbia University Press.

- Minkler, Lanse P. and Thomas J. Miceli. 2001. "Lying, Integrity, and Cooperation," Unpublished manuscript.

- $\quad$ Oxford Companion to Philosophy, Edited by Ted Honderich, Oxford: Oxford University Press, 1995.

- $\quad$ Sagoff, Mark. 1986. "Values and Preferences," Ethics 96: 301-316.

- $\quad$ Sen, Amartya K. 1977. "Rational Fools: A Critique of the Behavioral Foundations of Economic Theory," Philosophy and Public Affairs 6: 317-44.

- $\quad$ Smart, J.J.C., and Bernard Williams, 1973. Utilitarianism: For and Against. Cambridge: Cambridge University Press.

- $\quad$ Stigler, George and Gary Becker. 1977. "De Gustibus Non Est Disputandum,” The American Economic Review 67(2) : 76-90.

- Welch, Patrick J. and J. J. Mueller. 2001. "The Relationships of Religion to Economics," Review of Social Economy 59(2): 185-202.

- $\quad$ West, Edwin G. and Michael McKee. 1983. "De Gustibus Est Disputand um: The Phenomenon of 'Merit Wants' Revisited," The American Economic Review 73(5): 11101121. 
Figure 1

The Choice of Pork and Fish

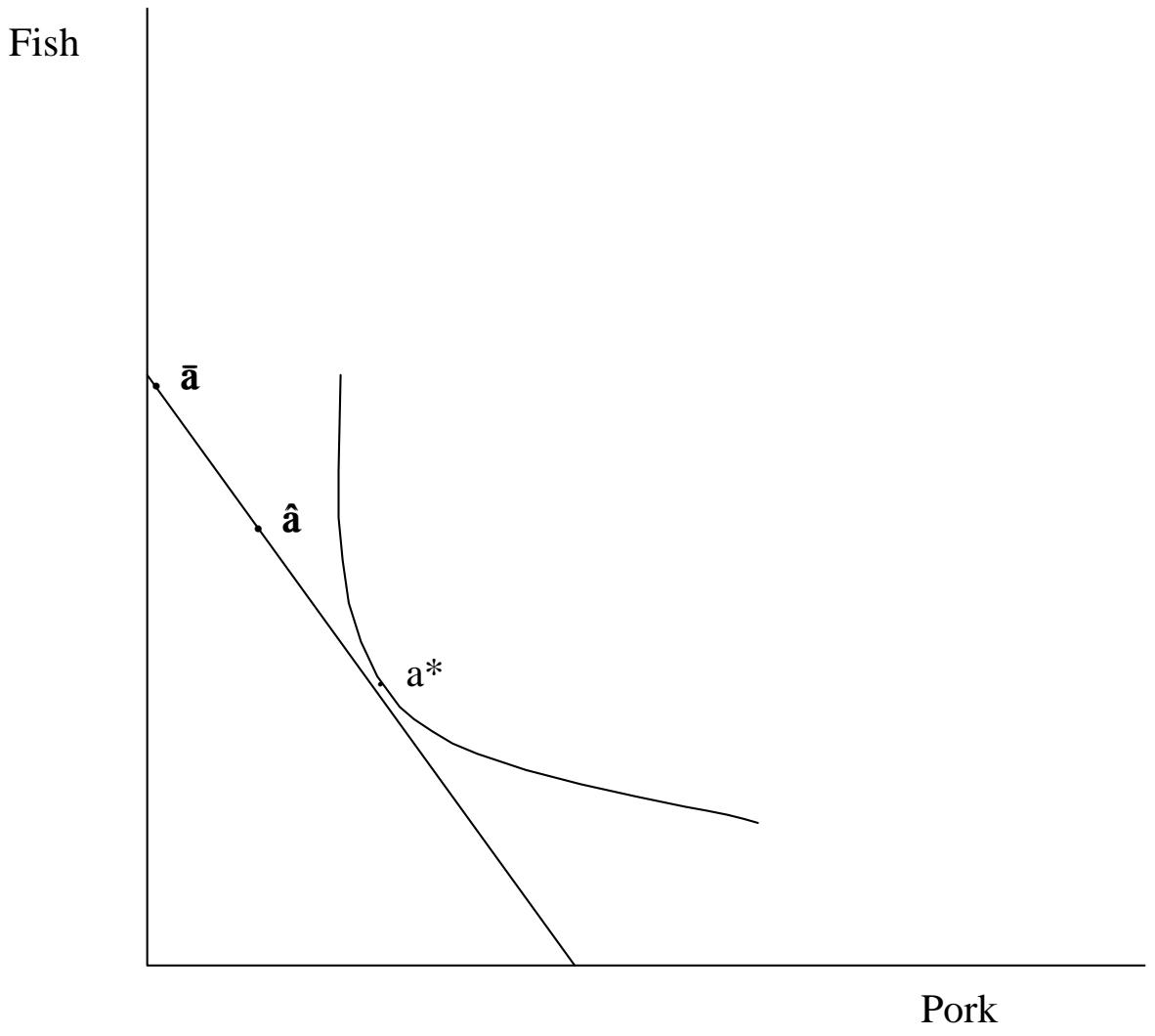


Figure 2

The Choice of Worship and Leisure

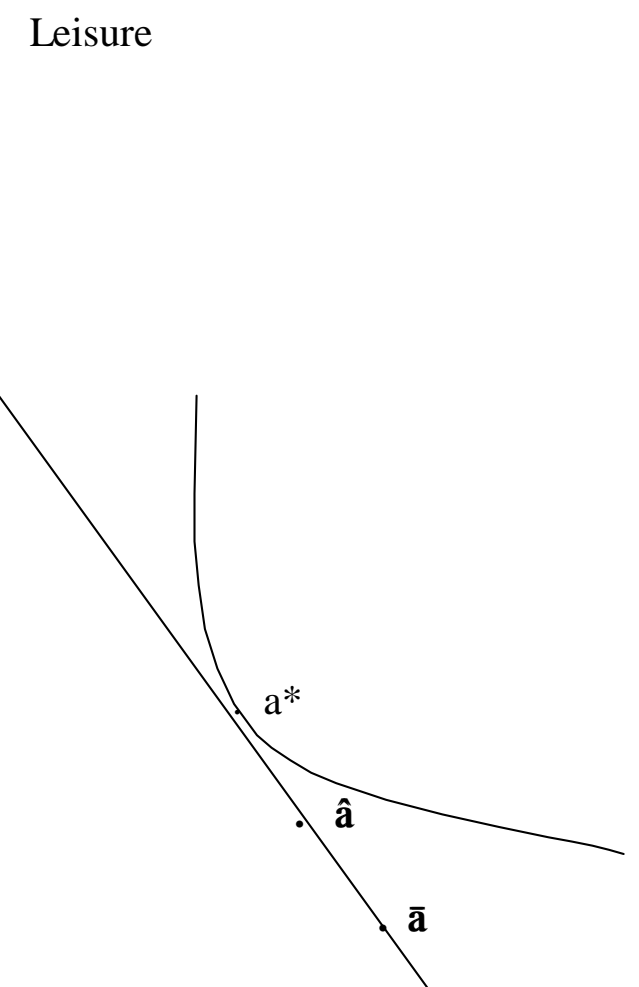

Worship 